\title{
ansa-METALLOCENE DERIVATIVES
}

\section{MOLECULAR STRUCTURE AND PROTON MAGNETIC RESONANCE SPECTRA OF METHYLENE- AND ETHYLENE-BRIDGED DICYCLOPEN'TADIENYLTITANIUM COMPOUNDS}

\author{
JAMES A. SMITH, JOACHIM VON SEYERL, GOTTFRIED HUTTNER * and \\ HANS H. BRINTZINGER * \\ Fachbereich Chemie, Universittät Konstanz, 7750 Konstanz (Bundesrepublik Deutschland)
}

\section{Summary}

The molecular structure of the methylene-bridged titanocene dichloride, $\mathrm{CH}_{2}\left(\mathrm{C}_{5} \mathrm{H}_{4}\right)_{2} \mathrm{TiCl}_{2}$, and that of the novel, ethylene-bridged derivative, $\left(\mathrm{CH}_{2}\right)_{2}$ $\left(\mathrm{C}_{5} \mathrm{H}_{4}\right)_{2} \mathrm{TiCl}_{2}$ have been determined by X-ray diffraction methods. In these molecules the cyclopentadienyl ligands are highly restricted in their torsional mobility. An angle of $65^{\circ}$ between the two ring planes, a $\mathrm{C}-\mathrm{C}-\mathrm{C}$ angle of $97.5^{\circ}$ at the methylene carbon atom, and other geometrical data, indicate a high degree of strain in the methylene-bridged derivative, whereas the ligand geometry of the ethylene-bridged derivative does not deviate significantly from that of unbridged titanocene dichloride.

${ }^{1} \mathrm{H}$ NMR spectra for ansa-titanocene derivatives of general type $\left(\mathrm{CH}_{2}\right)_{n^{-}}$$\left(\mathrm{C}_{5} \mathrm{H}_{4}\right)_{2} \mathrm{TiX}_{2}\left(n=1-3, \mathrm{X}=\mathrm{Cl}, \mathrm{CH}_{3}, \mathrm{CO}\right)$ are reported; the varying degrees of splitting between the high-field and the low-field portions of an $\mathrm{A}_{2} \mathrm{~B}_{2}$ resonance pattern due to the cyclopentadienyl hydrogen atoms are interpreted in terms of bonding geometries.

\section{Introduction}

ansa-Titanocene derivatives, which contain a covalent $\left(\mathrm{CH}_{2}\right)_{n}$ link between their cyclopentadienyl ligands $* *$, are useful as stereorigid model compounds for

* To whom correspondence should be addressed.

** The prefix ansa- (latin = bent handle, attached at both ends), originally proposed by Lüttringhaus [2] for bridged aromatic compounds, is used here to denote the presence of an inter-annular bridge in these titanocene derivatives. This notation has been traditionally applied to heteroatom derivatives, whereas the related suffix "-phane", as proposed by Cram (see ref. 3 and literature cited there) primarily applies to hydrocarbon compounds in which more than two atoms of an aromatic ring are incorporated into a larger carbocyclic ring system. 
a study of titanocene-based catalysis reactions (see e.g. ref. 1).

In order to provide a reliable structural basis for further investigations of the role of the dicyclopentadienyl ligand framework in catalytic reactions mediated by compounds of this type, we wish to report the crystal and molecular structure of the methylene-bridged 1-ansa-titanocene dichloride, $\mathrm{CH}_{2}\left(\mathrm{C}_{5} \mathrm{H}_{4}\right)_{2} \mathrm{TiCl}_{2}$ (Ia), prepared according to Katz and Acton [1], as well as that of the novel 2 -ansa-titanocene dichloride, $\left(\mathrm{CH}_{2}\right)_{2}\left(\mathrm{C}_{5} \mathrm{H}_{4}\right)_{2} \mathrm{TiCl}_{2}$ (IIa). We also report the ${ }^{1} \mathrm{H}$ NMR spectra of a number of ansa-titanocene derivatives, $\left(\mathrm{CH}_{2}\right)_{n}\left(\mathrm{C}_{5} \mathrm{H}_{4}\right)_{2} \mathrm{TiX}_{2}$, $\left(n=1-3\right.$ and $\mathrm{X}=\mathrm{Cl}, \mathrm{CH}_{3}, \mathrm{CO}$ ), and their interpretation in terms of varying bonding geometries in the titanocene framework.

\section{Experimental}

The compounds used were made by procedures reported in the literature [ 1 , 4] with some modifications [5]. Crystals of compound la were obtained from methylene chloride at $-40^{\circ} \mathrm{C}$; compound IIa was crystallized from toluene at room temperature.

Cell parameters and X-ray diffraction intensitities for these crystals were determined on a SYNTEX-P3 diffractometer at $173 \mathrm{~K}\left(\mathrm{Mo}-K_{\mathrm{a}}, \lambda 71.069 \mathrm{pm}\right.$, graphite monochromator, $\omega$-scan, $0.9<\dot{\omega} \leqslant 29.3^{\circ} \mathrm{min}^{-1}, 2 \leqslant 20 \leqslant 60^{\circ}$ for Ia and $2 \leqslant 2 \theta \leqslant 40^{\circ}$ for IIa; independent intensities measured: 1315 for compotind Ia, 994 for compound IIa. The crystals of compound Ia are triclinic, space group $P_{1} ; a$ 807.6(10), $b$ 809.2(10), $c 1011.8(10) \mathrm{pm}, \alpha 126.0(1)^{\circ}, \beta$ $97.9(1)^{\circ}, \gamma 95.2^{\circ} ; 2$ molecules per unit cell; $V 517.3 \times 10^{6} \mathrm{pm}^{3} ; d_{\text {calc }} 1.68$ $\mathrm{g} / \mathrm{cm}^{3}$; absorption coefficient $\mu 13 \mathrm{~cm}^{-1}$. The crystals of $\mathrm{Ila}$ are are monoclinic, space group $C 2 / c ; \alpha 1335.0(5), b 817.6(4), c 1267.3(6) \mathrm{pm} ; \alpha 90^{\circ}, \beta$ $123.92(3)^{\circ}, \gamma 90^{\circ} ; 4$ molecules per unit cell, $V 1147.98 \times 10^{6} \mathrm{pm}^{3} ; d_{\text {calc }} 1.60$ $\mathrm{g} / \mathrm{cm}^{3}$; absorption coefficient $\mu 12 \mathrm{~cm}^{-1}$. Empirical absorption corrections were applied to both data sets. The structures were solved by direct methods [6], using SYNTEX-EXTL equipment. Partially anisotropic refinement resulted in $R$ values of 0.053 and 0.055 for Ia and IIa, respectively.

The ${ }^{1} \mathrm{H}$ NMR spectra of the dichloro, dimethyl and dicarbonyl derivatives (the latter under exclusion of air) were obtained on a JEOL 100 continuous wave spectrometer.

\section{Results and discussion}

\section{Molecular structures *}

Structural data as well as bond iengths and bond angles pertaining to the coordination geometries of compounds Ia and IIa are listed in Table 1 and 2. The molecular structures obtained for these compounds are represented in Fig. 1, together with that of the trimethylene-bridged dichloro derivative $\left(\mathrm{CH}_{2}\right)_{3}\left(\mathrm{C}_{5} \mathrm{H}_{4}\right)_{2} \mathrm{TiCl}_{2}$ (IIIa), as reported by Bernal et al. [7,8]. Inspection of the individual structures reveals the following features.

\footnotetext{
* The following notations will be used: the ring carbon atoms to which the $\left(\mathrm{CH}_{2}\right)_{n}$ bridge is connected will be called the "bridgehead" atom: the two ring positions, which are immediately adjacent to this bridgehead atom, will be called "proximal" positions; the two positions which are farther remote from the bridgehead will be called "distal" positions.
} 
TABLE 1

STRUCTURAL PARAMETERS FOR $\mathrm{CH}_{2}\left(\mathrm{C}_{5} \mathrm{H}_{4}\right)_{2} \mathrm{TiCl}_{2}$

Interatomic distances in pm, bond angles in degrees, hydrogen atoms in calculated positions 100 pm from corresponding $C$ atom, $C p 1=$ centroid of ring 1 , plane $1=$ mean plane of ring 1 .

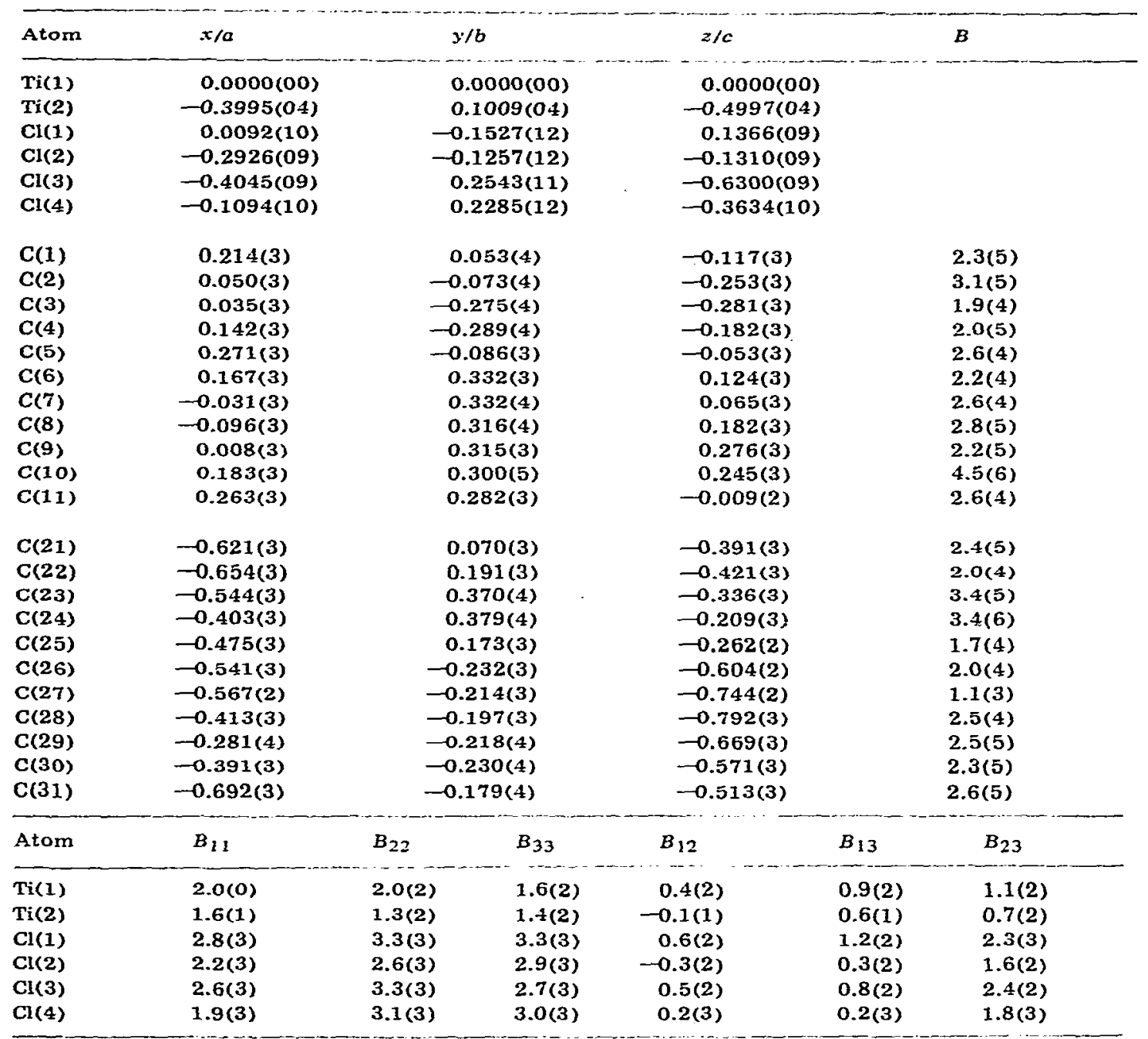

Interatomic distances

\begin{tabular}{|c|c|c|c|}
\hline $\operatorname{Ti}(1)-\mathrm{Cl}(1)$ & $233(1)$ & $\mathrm{Ti}(2)-\mathrm{Cl}(3)$ & $235(1)$ \\
\hline $\mathrm{Ti}(1)-\mathrm{Cl}(2)$ & $234(1)$ & $\mathrm{Ti}(2)-\mathrm{Cl}(4)$ & $234(1)$ \\
\hline $\operatorname{Ti}(1)-\mathrm{Cp}(1)$ & $205(2)$ & $\operatorname{Ti}(2)-C p(3)$ & $203(2)$ \\
\hline$T i(1)-C p(2)$ & $206(2)$ & $\mathrm{Ti}(2)-\mathrm{Cp}(4)$ & $205(3)$ \\
\hline $\operatorname{Ti}(1)-C(1)$ & $237(3)$ & $\mathrm{Ti}(2)-\mathrm{C}(2 \mathrm{I})$ & $230(3)$ \\
\hline$T i(1)-C(2)$ & $238(3)$ & $\mathrm{Ti}(2)-\mathrm{C}(22)$ & $233(2)$ \\
\hline$T i(1)-C(3)$ & $245(3)$ & $T i(2)-C(23)$ & $237(3)$ \\
\hline$T i(1)-C(4)$ & $248(3)$ & $T i(2)-C(24)$ & $245(3)$ \\
\hline $\operatorname{Ti}(1)-C(5)$ & $239(2)$ & $T i(2)-C(25)$ & $230(2)$ \\
\hline $\mathrm{Ti}(1)-\mathrm{C}(6)$ & $235(3)$ & $\mathrm{Ti}(2)-\mathrm{C}(26)$ & $233(3)$ \\
\hline $\operatorname{Ti}(1)-C(7)$ & $241(3)$ & $\operatorname{Ti}(2-C(27)$ & $234(2)$ \\
\hline$T i(1)-C(8)$ & $240(3)$ & $\mathrm{Ti}(2)-\mathrm{C}(28)$ & $246(2)$ \\
\hline$T i(1)-C(9)$ & $242(2)$ & $\operatorname{Ti}(2)-C(29)$ & $250(3)$ \\
\hline$T i(1)-C(10)$ & $234(3)$ & $T i(2)-C(30)$ & $234(3)$ \\
\hline$C(1)-C(11)$ & $146(4)$ & $c(21)-c(31)$ & $161(4)$ \\
\hline$c(6)-c(11)$ & $151(3)$ & $C(26)-C(31)$ & $157(3)$ \\
\hline
\end{tabular}


TABLE 1 (continued)

\begin{tabular}{|c|c|c|c|}
\hline \multicolumn{4}{|l|}{ Bond angles } \\
\hline $\mathrm{Cl}(1)-\mathrm{Ti}(1)-\mathrm{Cl}(2)$ & $97.2(3)$ & $\mathrm{CI}(3)-\mathrm{Ti}(2)-\mathrm{Cl}(4)$ & 97.0(3) \\
\hline$C(1)-C(11)-C(6)$ & $99(2)$ & $c(21)-c(31)-c(26)$ & $96(2)$ \\
\hline $\operatorname{Cp}(1)-\mathrm{Ti}-\mathrm{Cp}(2)$ & $121(1)$ & $\operatorname{Cp}(3)-T i(2)-C p(4)$ & $122(1)$ \\
\hline \multicolumn{4}{|c|}{ Angles relative to ring planes } \\
\hline$C(11)-C(1)$-plane 1 & 14 & $C(31)-C(21)$-plane 3 & 18 \\
\hline$C(11)-C(6)$-plane 2 & 14 & $C(31)-C(26)$-plane 4 & 16 \\
\hline plane 1 -plane 2 & 68 & plane 3-plane 4 & 63 \\
\hline
\end{tabular}

The methylene-bridged compound Ia crystallizes with two structurally independent molecules in its triclinic unit cell. These two molecules are quite similar in their essential structural features; in the following description, average distances and bond angles for both halves of each molecule are indicated, with mean deviations given in parentheses.

The two bonds connecting the bridgehead atoms $C(1)$ and $C(6)(C(21)$ and

TABLE 2

STRUCTURAL PARAMETERS FOR $\left(\mathrm{CH}_{2}\right)_{2}\left(\mathrm{C}_{5} \mathrm{H}_{4}\right)_{2} \mathrm{TiCl}_{2}$ Details as in Table 1

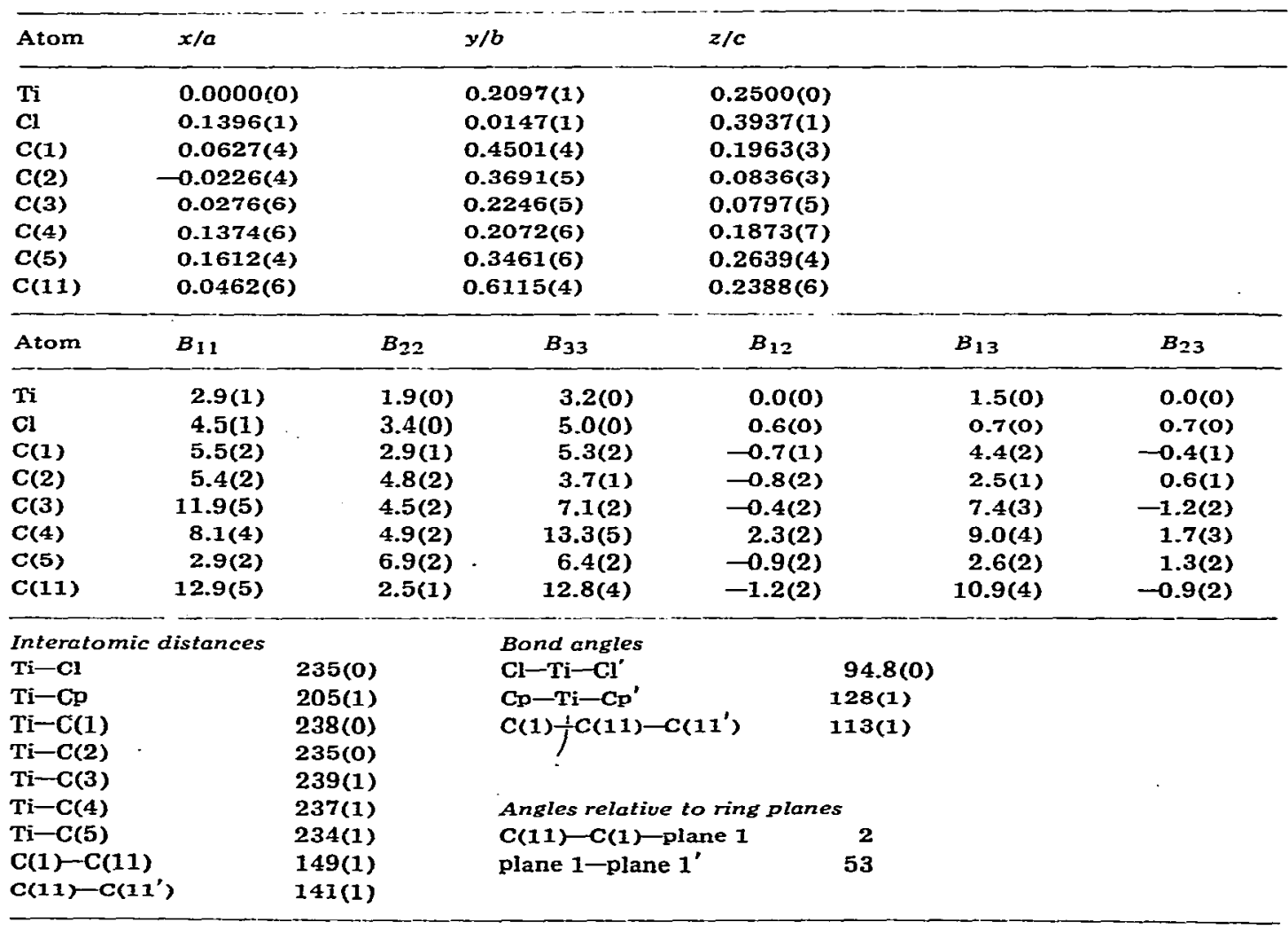



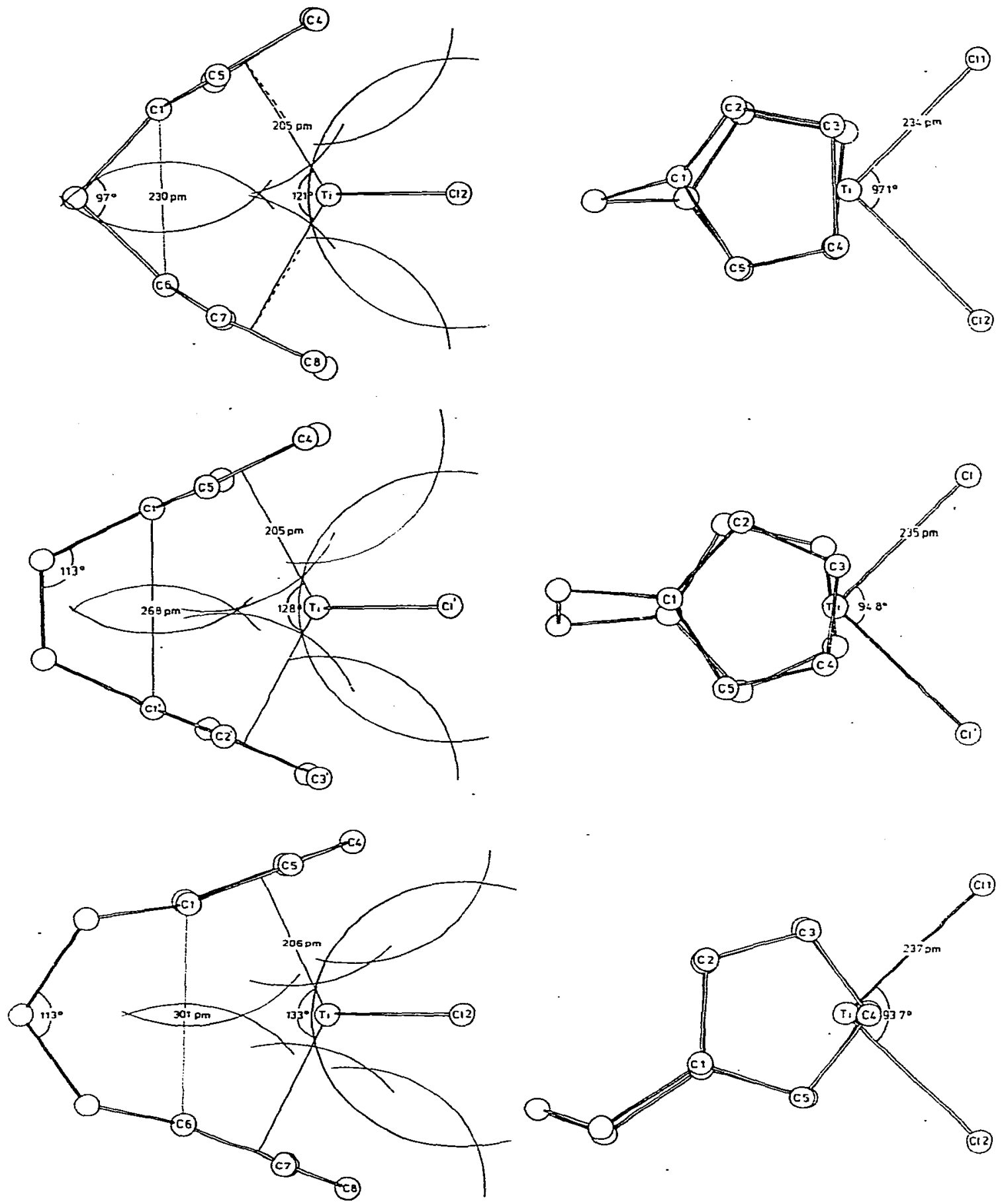

Fig. I. Molecular structures of $\mathrm{CH}_{2}\left(\mathrm{C}_{5} \mathrm{H}_{4}\right)_{2} \mathrm{TiCl}_{2}$ (Ia) (top) and $\left(\mathrm{CH}_{2}\right)_{2}\left(\mathrm{C}_{5} \mathrm{H}_{4}\right)_{2} \mathrm{TiCl}_{2}$ (IIa) (middle). Each structure is represented by two mutually perpendicular projections onto the $\mathrm{TiCl}_{2} \mathrm{plane}(\mathrm{right}$ ) and onto the plane bisecting the $\mathrm{Cl}-\mathrm{Ti}-\mathrm{Cl}$ angle (left). The large circular segments represent $\mathrm{Vander} W$ aals contact distances for aromatic carbon atoms $(165 \mathrm{pm})$ and for covalently bound chlorine atoms (180 pm) to indicate non-bonding contacts in these molecules. For comparison, corresponding projections of the structure of $\left(\mathrm{CH}_{2}\right)_{3}\left(\mathrm{C}_{5} \mathrm{H}_{4}\right)_{2} \mathrm{TiCl}_{2}$ (bottom) as reported by Bernal et al. [7,8] are included in this figure. 
$\mathrm{C}(26)$ ) to the $\mathrm{CH}_{2}$ bridging group, each with a bond length of $153(5) \mathrm{pm}$, form an unusually acute angle of $97(2)^{\circ}$ at the methylene carbon atom. Each of the cyclopentadienyl rings is bent further toward the titanium atom so that its mean plane deviates by $16(1)^{\circ}$ from the respective methylene-bridgehead bond. Accordingly, the two mean ring planes intersect at an angle of $65(3)^{\circ}$. This tilt angle represents a deviation by $44^{\circ}$ from that of two tetrahedrally connected $\left(\mathrm{C}_{5} \mathrm{H}_{4}\right)-\mathrm{CH}_{2}-\left(\mathrm{C}_{5} \mathrm{H}_{4}\right)$ bonds, each coplanar with its adjacent cyclopentadienyl ring. This substantial distortion of the $\mathrm{CH}_{2}\left(\mathrm{C}_{5} \mathrm{H}_{4}\right)_{2}$ framework is not yet sufficient to accommodate the coordination requirements of the titanium atom: The two ring centroid-titanium connections form a $\mathrm{Cp}-\mathrm{Ti}-\mathrm{Cp}$ angle of $121(1)^{\circ}$ at the titanium atom; each of these connections thus deviates by $3-$ $4^{\circ}$ from the direction normal to the mean plane of its cyclopentadienyl ring. In this manner, the mean ring centroid-titanium $(\mathrm{Cp}-\mathrm{Ti})$ distance acquires a value of $205(1.5) \mathrm{pm}$, which is quite similar to $\mathrm{Cp}-\mathrm{Ti}$ distances observed, e.g. in $\left(\mathrm{C}_{5} \mathrm{H}_{4}\right)_{2} \mathrm{TiCl}_{2}$ [9] and in $\left(\mathrm{CH}_{2}\right)_{3}\left(\mathrm{C}_{5} \mathrm{H}_{4}\right)_{2} \mathrm{TiCl}_{2}[7,8]$, while the individual ring carbon-titanium distances are no longer equal, ranging from 234(3) pm for carbon atoms in bridgehead positions to $244(5) \mathrm{pm}$ for those in distal positions. The small $\mathrm{Cp}-\mathrm{Ti}-\mathrm{Cp}$ angle of $121^{\circ}$ is accompanied by a significantly enlarged $\mathrm{Cl}-\mathrm{Ti}-\mathrm{Cl}$ angle of $97.1(0.1)^{\circ}$ compared to $94.4^{\circ}$ in $\left(\mathrm{C}_{5} \mathrm{H}_{5}\right)_{2} \mathrm{TiCl}_{2}$ [9]. An apparent shortening of the mean $\mathrm{Ti}-\mathrm{Cl}$ bond length to $234(1) \mathrm{pm}$, compared to $235 \mathrm{pm}$ in $\left(\mathrm{C}_{5} \mathrm{H}_{5}\right)_{2} \mathrm{TiCl}_{2}$ [9] and to $236.8 \mathrm{pm}$ in $\left(\mathrm{CH}_{2}\right)_{3}\left(\mathrm{C}_{5} \mathrm{H}_{4}\right)_{2} \mathrm{TiCl}_{2}[7,8]$, is only marginally significant.

Further distortions of the $\mathrm{CH}_{2}\left(\mathrm{C}_{5} \mathrm{H}_{4}\right)_{2}$ framework are found for $\mathrm{C}-\mathrm{C}$ distances within each ring, for which a range from 120 to $167 \mathrm{pm}$ is obtained. Part of this spread is undoubtedly an artifact, possibly due to the unfavourably thin shape of the crystal plates obtained for this compound. The general pattern of this distortion within each ring appears to be such, however, that a three-carbon allyl segment $(C(1)-C(2)-C(3)$ and $C(6)-C(7)-C(8))$ within each ring is separated from the remaining olefinic two-carbon segment by two single bonds. Such a distortion might be related to the fact that in the $\mathrm{CH}_{2}\left(\mathrm{C}_{5} \mathrm{H}_{4}\right)_{2} \mathrm{TiCl}_{2}$ structure the short methylene bridge brings the aromatic ring ligands in close contact with each other, their bridgehead positions being separated by no more than $230 \mathrm{pm}$. By comparison, e.g. with an interlayer distance of about $330 \mathrm{pm}$ in graphite, or with ring-to-ring distances of about $270 \mathrm{pm}$ in various cyclophanes [3], one would expect that such a mutual encroachment would induce a severe repulsive interaction between the two $\pi$-electron systems. The ring distortion described above (i.e. toward an allylic and an olefinic segment) might serve to remove the bridgehead carbon atoms from their eclipsed positions and thereby reduce their repulsive interaction. However, all the cyclopentadienyl $\mathrm{C}$ atoms remain within $5 \mathrm{pm}$ from the mean plane of the cyclopentadienyl ring.

Furthermore, the overall structure of the molecule is slightly distorted in that the two ring-centroid titanium connections intersect with the $\mathrm{TiCl}_{2}$ plane at angles which differ by $2^{\circ}$, and by a displacement of the methylene carbon atom by $15(4) \mathrm{pm}$ away from the axis bisecting the two $\mathrm{Ti}-\mathrm{Cl}$ bonds.

Altogether, it seems that the structure of $\mathrm{CH}_{2}\left(\mathrm{C}_{5} \mathrm{H}_{4}\right)_{2} \mathrm{TiCl}_{2}$, which could be described as containing a four-membered chelate ring, Ti-C(1)-CH $-\mathrm{C}(6)$, is appreciably strained in order to accomodate the bonding requirements at the methylene bridge as well as those at the titanium centre. 
In contrast to the rather strained structure of compound $\mathrm{Ia}$, no significant distortion from the geometry of an unbridged titanocene derivative are noticeable in the structure of the 1,2-ethylene-bridged compound IIa, $\left(\mathrm{CH}_{2}\right)_{2}\left(\mathrm{C}_{5} \mathrm{H}_{4}\right)_{2}$ $\mathrm{TiCl}_{2}$. The monoclinic unit cell of this compound contains four symmetryrelated molecules; in addition each molecule is situated on a crystallographic $C_{2}$ axis which bisects the $\mathrm{Cl}-\mathrm{Ti}-\mathrm{Cl}$ bond angle.

The $\mathrm{H}_{2} \mathrm{C}-\mathrm{C}(1)$ and $\mathrm{H}_{2} \mathrm{C}-\mathrm{C}\left(1^{\prime}\right)$ bonds connecting the cyclopentadienyl rings with the ethylene bridge (bond length, $149 \mathrm{pm}$ ) form an angle of $113^{\circ}$ with the central $\mathrm{H}_{2} \mathrm{C}-\mathrm{CH}_{2}$ bond. A similar positive deviation from a tetrahedral angle has previously been found in the trimethylene bridge of $\left(\mathrm{CH}_{2}\right)_{3}\left(\mathrm{C}_{5} \mathrm{H}_{4}\right)_{2} \mathrm{TiCl}_{2}$ $[7,8]$. The $B$ values indicate a substantial degree of rotational motion, especially for the $\mathrm{CH}_{2}$ carbon atoms, which may affect the physical significance of the observed bond lengths to some extent. The $\mathrm{H}_{2} \mathrm{C}-\mathrm{C}(1)$ bonds are coplanar to within less than $2^{\circ}$ with the adjacent cyclopentadienyl ring. Due to a slight inclination of the central $\mathrm{H}_{2} \mathrm{C}-\mathrm{CH}_{2}$ bond $\left(18.5^{\circ}\right.$ from the $\mathrm{Cl}-\mathrm{Ti}-\mathrm{Cl}$ bisector plane), the two cyclopentadienyl rings are no longer as closely eclipsed as in the structure of Ia; instead, they are twisted by a torsional angle of $12(0.5)^{\circ}$ in relation to each other about their respective centroid $\mathrm{Cp}-\mathrm{Ti}$ axes. The $\mathrm{C}-\mathrm{C}$ distances within each ring are within a narrow range of 137 to 141 pm, while individual ring carbon-titanium distances are within a similarly narrow range of 234 to $239 \mathrm{pm}$, without any systematic differences between bridgehead, proximal and distal carbon atoms. The two centroid $\mathrm{Cp}-\mathrm{Ti}$ connections, with a $\mathrm{Cp}-\mathrm{Ti}$ distance of $206 \mathrm{pm}$, intersect at an angle of $128.2^{\circ}$ at the titanium atom. These $\mathrm{Cp}-\mathrm{Ti}$ connections coincide within less than $1^{\circ}$ with the directions normal to the mean plane of each ring. Accordingly, the two ring planes are found to intersect at an angle of $51.8^{\circ}$. This ring inclination is quite similar to the corresponding tilt angle of $49.5^{\circ}$ observed in unbridged $\left(\mathrm{C}_{5} \mathrm{H}_{5}\right)_{2}-$ $\mathrm{TiCl}_{2}$ [9]. Likewise, closely similar $\mathrm{Cl}-\mathrm{Ti}-\mathrm{Cl}$ angles of $94.8^{\circ}$ and $94.4^{\circ}$ are found in $\left(\mathrm{CH}_{2}\right)_{2}\left(\mathrm{C}_{5} \mathrm{H}_{4}\right)_{2} \mathrm{TiCl}_{2}$ and $\left(\mathrm{C}_{5} \mathrm{H}_{5}\right)_{2} \mathrm{TiCl}_{2}$ [9], respectively. It is apparent that in the structure of $\left(\mathrm{CH}_{2}\right)_{2}\left(\mathrm{C}_{5} \mathrm{H}_{4}\right)_{2} \mathrm{TiCl}_{2}$, which could be regarded as containing a five-membered $\mathrm{Ti}-\mathrm{C}(1)-\mathrm{CH}_{2}-\mathrm{CH}_{2}-\mathrm{C}\left(1^{\prime}\right)$ chelate ring, the dimensions of the 1,2-ethylene bridge match up well to the coordination requirements of the titanium centre for two ring ligands with a mutual inclination of about $50^{\circ} \%$.

Inspection of the structures in Fig. 1 indicates that the ligand framework of the methylene- and ethylene-bridged derivatives has little freedom for torsional ring motions. Some useful information about the remaining torsional mobility can be obtained from ${ }^{1} \mathrm{H}$ NMR spectra of these and some related ansa-titanocene derivatives.

\section{Proton magnetic resonance spectra}

As previously noted for the ansa-titanocene dichloro derivatives $\mathrm{CH}_{2}\left(\mathrm{C}_{5} \mathrm{H}_{4}\right)_{2}$ -

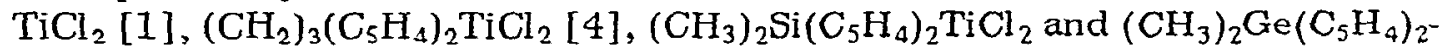
$\mathrm{TiCl}_{2}[13]$ as well as for a number of bridged ferrocene derivatives $[10,11]$, the

\footnotetext{
* In contrast, the requirement of an iron centre for an axial disposition of two cyclopentadienyl rings is severely distorted by the presence of a tetramethyl ethylene bridge in $\left(\left(\mathrm{CH}_{3}\right)_{2} \mathrm{C}_{2}\right.$ $\left(\mathrm{C}_{5} \mathrm{H}_{4}\right)_{2} \mathrm{Fe}[10-12]$.
} 
most informative feature in the ${ }^{1} \mathrm{H}$ NMR spectra of these compounds is the appearance of one symmetrical $A_{2} B_{2}$ resonance pattern for the cyclopentadienyl protons of both rings. The ${ }^{1} \mathrm{H}$ NMR data summarized in Table 3 shows that this observation holds for all ansa-titanocene derivatives of general type $\left(\mathrm{CH}_{2}\right)_{n}\left(\mathrm{C}_{5} \mathrm{H}_{4}\right)_{2} \mathrm{TiX}_{2}\left(n=1-3, \mathrm{X}=\mathrm{Cl}, \mathrm{CH}_{3}, \mathrm{CO}\right)$. These data (see Table 3) clearly indicate that the ligand framework structures of Ia, IIa and IIIa, as represented in Fig. 1, must interconvert with their mirror image counterparts fast enough to bring about an equivalence among all proximal hydrogen atoms and among all distal hydrogen atoms on the NMR time scale in solution at room temperature. For such an interconversion only minimal motions along a ring distorsion coordinate are required in the case of the 1-ansa--titanocene dichloride Ia, while for the 2-ansa derivative IIa a mutual torsion of both rings by only $12^{\circ}$ brings about such an interconversion. Both Ia and IIa deviate from $C_{2 v}$ symmetry only to a limited extent. The ring motions required for an interconversion of structures Ia and IIa to their respective mirror image counterparts are, therefore, restricted to such a degree that their distal ring positions always remain in the central region of the molecule (i.e. in close vicinity to the plane through the Ti centre which is perpendicular to both the $\mathrm{TiX}_{2}$ plane and the $\mathrm{Cl}-\mathrm{Ti}-\mathrm{Cl}$ bisector plane), while the proximal ring positions are retained in the lateral regions of the molecule. In contrast to this, an interconversion of the

TABLE 3

${ }^{1}$ H NMR DATA OF ANSA-TITANOCENE DERIVATIVES $\left(\mathrm{CH}_{2}\right)_{n}\left(\mathrm{C}_{5} \mathrm{H}_{4}\right)_{2} \mathrm{TIX}_{2}$ $n=1-3 ; \mathrm{X}=\mathrm{Cl}, \mathrm{CH}_{3} . \mathrm{CO}$; chemical shifts $\delta$ in ppm relative to $\delta\left(\mathrm{CHCl}_{3}\right)=7.24$ ppm: relative intensities in parentheses

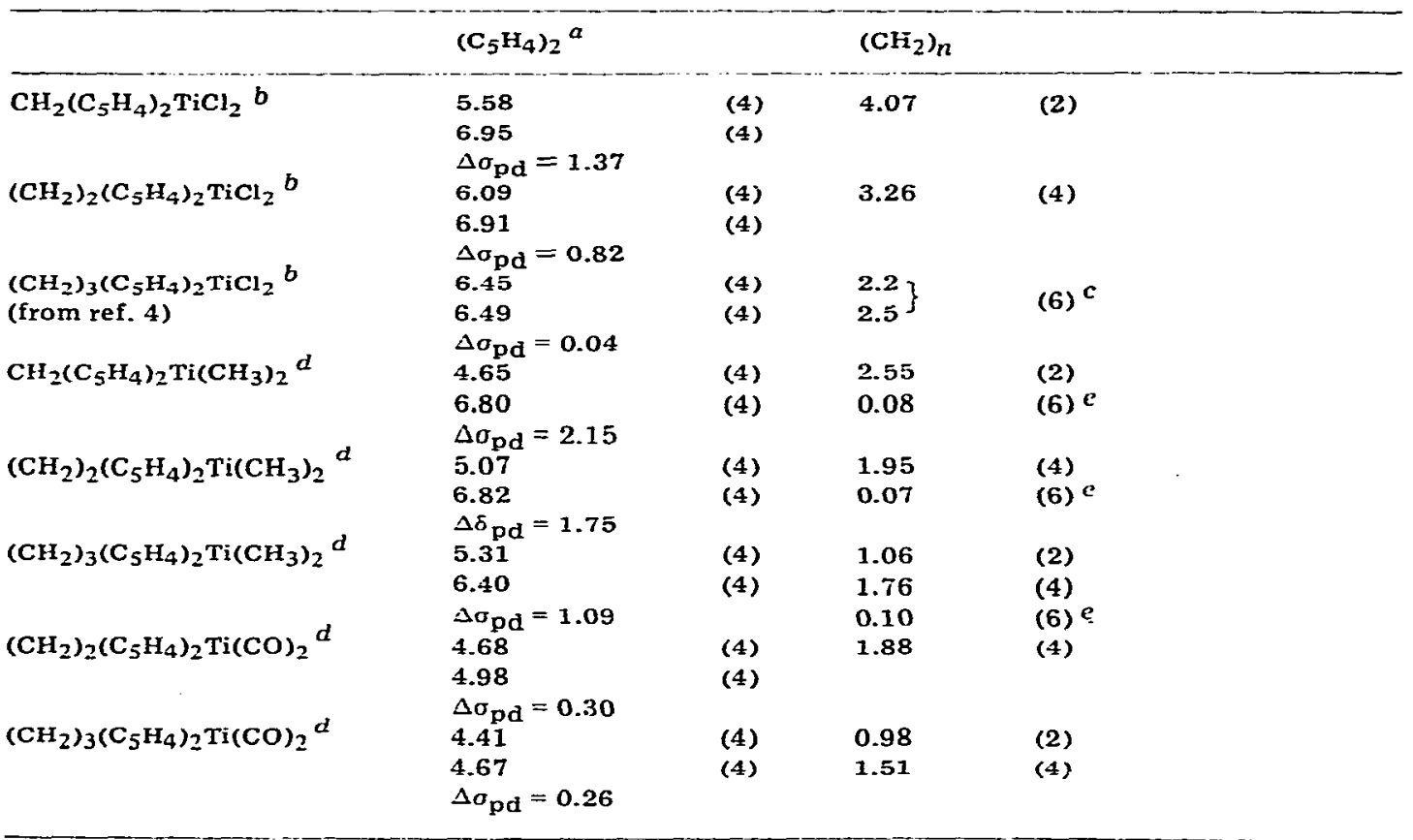

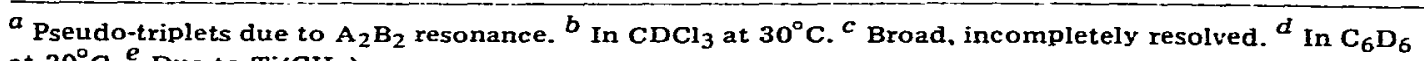
at $30^{\circ} \mathrm{C}$. $e$ Due to $\mathrm{Ti}\left(\mathrm{CH}_{3}\right)_{2}$ groups. 
3-ansa-titanocene structure IIIa to its mirror image counterpart requires a mutual torsion of both rings by $72^{\circ}$, together with an inversion of the folded six-membered $\mathrm{Ti}-\mathrm{C}(1)-\mathrm{CH}_{2}-\mathrm{CH}_{2}-\mathrm{CH}_{2}-\mathrm{C}(6)$ chelate ring into its opposite chair conformation. This process must, therefore, interchange the distal ring positions between central and lateral regions of the molecule and the proximal ring positions between laterai and dorsal (i.e. backside) regions of the molecule.

This variation in ring mobility undoubtedly contributes to the variation in chemical shift differences, $\Delta \sigma_{\mathrm{pd}}$, between proximal and distal ring hydrogen atoms observed for these compounds $[1,4]$ : While differences in chemical shifts between the individual positions of structure IIIa will be partly averaged out by the fairly large degree of torsional ring mobility compatible with the "slack" of its trimethylene bridge, little if any such averaging could reduce $\Delta \sigma_{\mathbf{p d}}$ values in the rather rigid structures of Ia and IIa.

Concerning the physical origins of this, diagnostically rather useful, ${ }^{1} \mathrm{H}$ NMR splitting between proximal and distal hydrogen atoms, we can base the following arguments on a correlation of $\Delta \sigma_{\mathrm{pd}}$ values in the $n$-ansa-titanocene derivatives considered here with their respective structures.

(i) The (average) disposition of proximal and of distal ring positions relative to the Ti centre shows only minimal differences between Ia and IIa. It appears rather unlikely, therefore, that differences in shielding by the titanium centre could explain the substantial difference between $\Delta \sigma_{\mathrm{pd}}=1.36 \mathrm{ppm}$ for Ia [1] and $\Delta \sigma_{\mathrm{pd}}=0.82 \mathrm{ppm}$ for IIa.

(ii) Due to their mutual inclination, each of the ring ligands must produce an anisotropic shielding for the hydrogen atoms of the other ring, the extent of which will be greater for the distal than for the proximal ring positions, since the distal hydrogen atoms are closer to the central axis of the opposite ring. It is apparent from Fig. 1, however, that the increased ring tilt angle in structure Ia places the distal hydrogen atoms at an increased rather than at a decreased distance from the central axis of the other ring. Changes in anisotropic shielding effects with the inclination angle between the two ring planes can, therefore, not explain the increased splitting $\Delta \sigma_{\mathrm{pd}}$ observed for Ia as compared to that of IIa.

(iii) The repulsive approach of the two aromatic rings at their bridgehead positions must induce a shift of $\pi$-electron density away from the bridgehead toward the distal ring positions; the extent of this shift in $\pi$-electron density must be greater for the 1-ansa-derivative Ia, with a $C(1)-C(6)$ distance of only $230 \mathrm{pm}$, than for its 2-ansa homologue IIa, in which $C(1)$ and $C\left(1^{\prime}\right)$ are separated by about $270 \mathrm{pm}$. The ensuing excess of $\pi$-electron density at the respective distal ring positions would thus provide a plausible explanation for the observed increase in ${ }^{1} \mathrm{H}$ NMR splitting, $\Delta \sigma_{\mathrm{pd}}$, of Ia over that of IIa.

This model for the origin of the ${ }^{1} \mathrm{H}$ NMR splitting in bridged titanocenes is supported by ${ }^{13} \mathrm{C}$ NMR spectra obtained for compounds Ia, IIa and IIIa in $\mathrm{CD}_{2} \mathrm{Cl}_{2}$ solution (see Table 4; compound Ia proved too insoluble for exact integration). While some splitting over a range of about $7 \mathrm{ppm}$ is observed for the ring carbon atoms of the trimethylene-bridged derivative IIIa, this splitting is increased to about $25 \mathrm{ppm}$ in IIa and to about $33 \mathrm{ppm}$ in Ia. The low-field shift of the bridgehead carbon atom is clearly recognizable in this spectrum, indicating a particularly low $\pi$-electron density at this position. Interestingly, the 
TABLE 4

${ }^{13} \mathrm{C}$ NMR DATA OF $\mathrm{CH}_{2}\left(\mathrm{C}_{5} \mathrm{H}_{4}\right)_{2} \mathrm{TiCl}_{2},\left(\mathrm{CH}_{2}\right)_{2}\left(\mathrm{C}_{5} \mathrm{H}_{4}\right)_{2} \mathrm{TiCl}_{2}$ AND $\left(\mathrm{CH}_{2}\right)_{3}\left(\mathrm{C}_{5} \mathrm{H}_{4}\right)_{2} \mathrm{TiCl}_{2}$

Spectra taken on Bruker WP $80 \mathrm{FT}$ with proton broad band decoupling, in $\mathrm{CD}_{2} \mathrm{Cl}_{2}$ solution at $-40^{\circ} \mathrm{C}$;

chemical shifts $\delta$ in ppm relative to $\delta\left(\mathrm{CD}_{2} \mathrm{Cl}_{2}\right)=\$ 33.60 \mathrm{ppm}$; relative intensities in parentheses

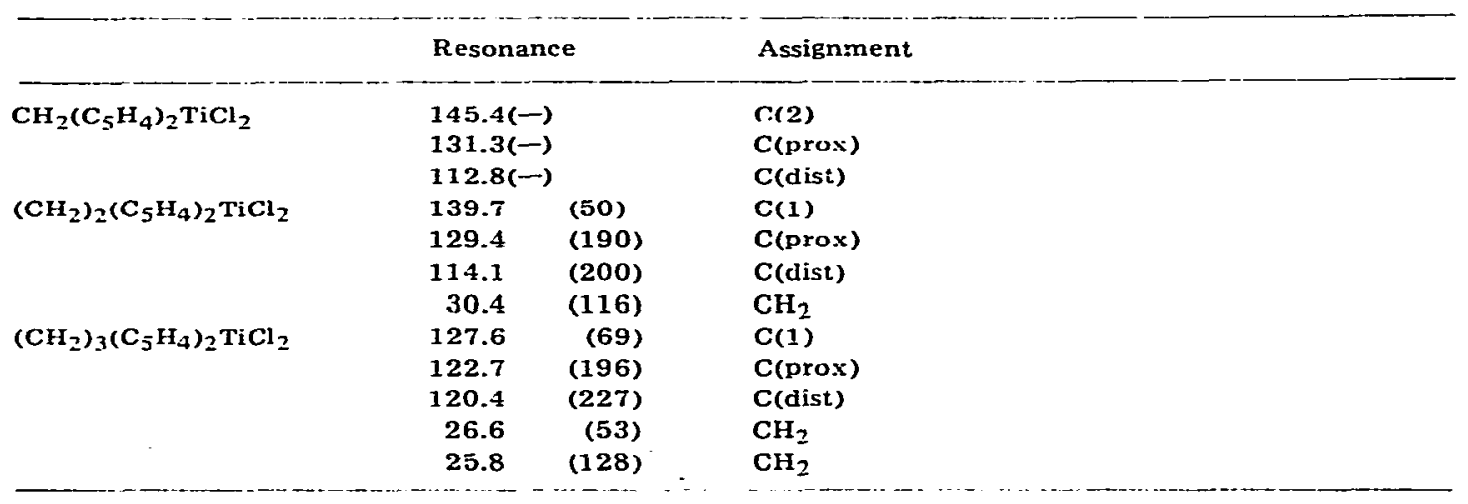

average shift of all five ring positions remains virtually unchanged in the ${ }^{13} \mathrm{C}$ NMR spectra of III and IIa; this observation is in accord with the notion that the observed splittings arise from a re-distribution of a constant total $\pi$-electron population within each ring ligand.

Effects of different ligands in the $\mathrm{TiX}_{2}$ plane are also reflected in the ${ }^{1} \mathrm{H}$ NMR splitting patterns of these compounds. In the dimethyl derivatives Ib, IIb and IIIb, substantially larger $\Delta \sigma_{\mathrm{pd}}$ values are observed than in the corresponding dichloro derivatives. Conceivably, the electron density of the $\mathrm{CH}_{3}$ ligand groups does not overlap as extensively with the central region of the aromatic $\pi$-electron system and is, therefore, less effective than the rather bulky $\mathrm{Cl}$ ligands in counteracting $\pi$-electron shifts toward this region of the molecule.

In the dicarbonyl derivatives IIc and IIIc, on the other hand, reduced $\Delta \sigma_{\mathrm{pd}}$ values around $0.3 \mathrm{ppm}$ are observed, with hardly any dependence on the bridge-length parameter $n$. The $\pi$-electron system of the CO ligands apparently counteracts the effects of cyclopentadienyl $\pi$-electron shifts, be it by repulsive overlap with distal ring positions or by anisotropic shielding effects, which might be more sizeable for $\mathrm{CO}$ than for $\mathrm{Cl}$ or for $\mathrm{CH}_{3}$ ligands.

At any rate, we can safely assume that a change of ligand $\mathrm{X}$ in $\left(\mathrm{CH}_{2}\right)_{n}\left(\mathrm{C}_{5} \mathrm{H}_{4}\right)_{2^{-}}$ $\mathrm{TiX}_{2}$ would primarily affect the chemical environment of the centrally located distal hydrogen atoms. The observation, documented in Table 3, that the highfield portion of each cyclopentadienyl $-A_{2} B_{2}$ resonance is more strongly dependent on the nature of $\mathrm{X}$ than the respective low-field part then allows us to assign the high-field portion of this $A_{2} B_{2}$ resonance to the distal pair of hydrogen atoms *. This experimental assignment is in accord with the prediction of the $\pi$-electron polarization model proposed above.

Effects of decreased ring mobility in ansa-titanocene derivatives on some of their basic chemical reaction modes will be discussed in subsequent communications.

* A similar conclusion has previously been reached concerning the ${ }^{1} \mathrm{H}$ NMR spectra of $\left(\mathrm{CH}_{3}\right)_{2} \mathrm{Si}_{-}$ $\left(\mathrm{C}_{5} \mathrm{H}_{4}\right)_{2} \mathrm{Ti}$ and $\left(\mathrm{CH}_{3}\right)_{2} \mathrm{Ge}\left(\mathrm{C}_{5} \mathrm{H}_{4}\right)_{2} \mathrm{Ti}$ derivatives [13]. 


\section{Acknowledgements}

This research work was supported by grants from Deutsche Forschungsgemeinschaft and from Fonds dex Chemischen Industrie as well as by research funds of the University of Konstanz. We wish to thank Dr. H.D. Müller and Dr. G. Mohr for help in obtaining ${ }^{13} \mathrm{C}$ NMR spectra and Dr. L.G. Bell for several samples of $\left(\mathrm{CH}_{2}\right)_{3}\left(\mathrm{C}_{5} \mathrm{H}_{4}\right)_{2}$ Ti derivatives.

\section{References}

1 T.J. Katz and N. Acton, Tetrahedron Lett., 28 (1970) 2497.

2 A. Lüttringhaus and H. Gralheer, Ann., 550 (1942) 67.

3 D.J. Cram and J.M. Cram, Acc. Chem. Res., 4 (1971) 204.

4 M. Hillman and A.J. Weiss, J. Organometal. Chem.. 42 (1972) 123.

5 J.A. Smith and H.H. Brintzinger, in preparation.

6 G. Germain, P. Main and M.M. Woolfson, Acta Cryst., A, 27 (1971) 368.

7 C.H. Saldarriaga-Molina, A. Clearfield and I. Bernal. J. Organometal. Chem., 80 (1974) 79.

8 E.F. Epstein and I. Bernal, Inorg. Chim. Acta, 7 (19广3) 211.

9 A. Clearfield, D.K. Warner, C.H. Saldarnaga-Molina, R.Ropal and I. Bernal, Can. J. Chem., 53 (1975) 1622.

10 T.H. Barr and W.E. Watts, Tetrahedron, 24 (1968) 6111.

11 H.L. Lentzner and W.E. Watts, Tetrahedron, 27 (1971) 4343.

12 M.B. Laing and K.N. Trueblood, Acta Cryst., 19 (1965) 373.

13 H. Köpf and W. Kahl, J. Organometal. Chem., 64 (1974) C37. 